\title{
FREE N-ACETYLGLUCOSAMINE IN MARSUPIAL SEMEN
}

\author{
J. G. RODGER AND I. G. WHITE \\ Department of Veterinary Physiology, \\ University of Sydney, New South Wales, 2006, Australia
}

(Received 19th December 1973)

Appreciable quantities of a compound, now identified as $\mathrm{N}$-acetylglucosamine, have been found in deproteinized, deionized aqueous extracts of the seminal plasma of the red kangaroo (Megaleia rufa), tammar wallaby (Macropus eugenii), grey kangaroo (Macropus giganteus) and the ventral segment of the two segmented prostate gland (Rodger \& Hughes, 1973) of the long-nosed bandicoot (Perameles nasuta).

Sperm-free seminal plasma was collected by electroejaculation (J. C. Rodger and I. G. White, in preparation) 5 to 15 min after death from tammar wallabies on Kangaroo Island, South Australia, and red and grey kangaroos near Coonamble, N.S.W. The material was handled and extracts made in much the same manner as that described for prostatic tissue collected in the field (Rodger \& White, 1974). Weighed portions (approx. 0.5 to $1.0 \mathrm{~g}$ ) of coagulated seminal plasma were homogenized in distilled water then deproteinized by the addition of $10 \mathrm{ml}$ of $5 \% \mathrm{ZnSO}_{4} .7 \mathrm{H}_{2} \mathrm{O}$ and $10 \mathrm{ml}$ of $0.3 \mathrm{~N}$ $\mathrm{Ba}(\mathrm{OH})_{2}$. After centrifuging, the supernatant was passed through a mixed bed deionizing resin (equal volumes of Zeo-Karb 225 and Deacidite FF) to remove ions that would interfere with chromatography. The deionized eluant was freeze-dried and the residue dissolved in a suitable volume of distilled water. This aqueous extract was frozen till needed. At no time was the material exposed to extremes of $\mathrm{pH}$ or temperatures above $4^{\circ} \mathrm{C}$ and it seems unlikely that hydrolytic breakdown of polysaccharides would occur as a result of the procedures. As a check, sucrose was subjected to the extraction procedure and there was no evidence of glucose production using the glucose oxidase method (Werner, Rey \& Weilinger, 1970).

The compound was detected and its characteristics examined by descending paper chromatography on Whatman $3 \mathrm{~mm}$ paper. Five different solvent systems were employed (Table 1), a number of pure sugars being tested for comparison. The silver nitrate method of Trevelyan, Procter \& Harrison (1950) was used to detect sugars on the paper. The only sugar found to have the same mobility as the unknown in the solvent systems used was $\mathrm{N}$-acetylglucosamine (Text-fig. 1). The material was tested to find out if it was susceptible to acid hydrolysis as the acetyl group of $\mathrm{N}$-acetylglucosamine is removed by acid conditions. Hydrolysis of semen extracts with $0.8 \mathrm{M}-\mathrm{HCl}$ for $1 \mathrm{hr}$ at $100^{\circ} \mathrm{C}$ resulted in disappearance of the unidentified substance but yielded a ninhydrin-reactive product, not found in the unhydrolysed extracts, 
which behaved as glucosamine in the solvent systems used (Text-fig. 1). The unhydrolysed unidentified substance, like $\mathrm{N}$-acetylglucosamine, was not ninhydrin-reactive. Fructose, a common constituent of mammalian seminal plasma, was absent from extracts of the marsupial seminal plasma but con-

Table 1. Results of paper chromatography of a compound identified as $\mathrm{N}$-acetyl-glucosamine, found in the seminal plasma of three species of macropod and the prostate of one species of peramelid marsupial

\begin{tabular}{l|c}
\hline \multicolumn{1}{c|}{ Solvent $(v / v)$} & $\mathbf{R} \mathbf{g}^{*}$ \\
\hline Butanol : ethanol : water, $5: 1: 4$ (top layer) & $1 \cdot 50$ \\
Isopropanol : water, $4: 1$ & $1 \cdot 22$ \\
n-Propanol : ethyl acetate : water, $7: 1: 2$ & $1 \cdot 46$ \\
Ethyl acetate : pyridine : water, $12: 5: 4$ & $1 \cdot 23$ \\
Ethyl methyl ketone : glacial acetic acid : water saturated & $2 \cdot 05$ \\
with boric acid, $9: 1: 1$ & \\
\hline
\end{tabular}

* Mobility relative to glucose.

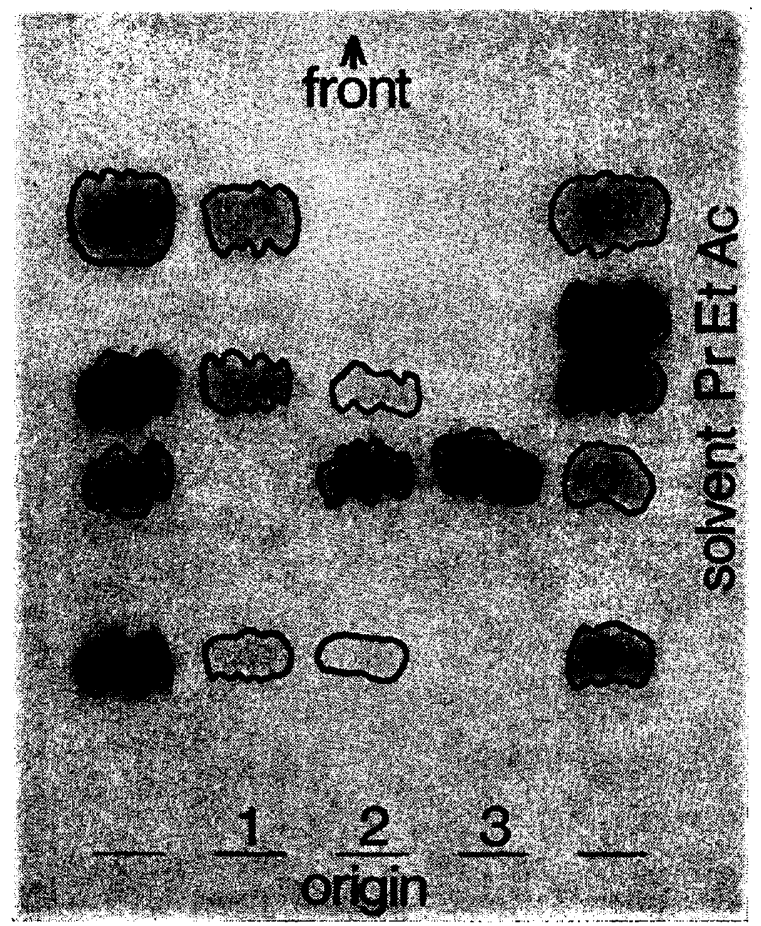

TEXT-FIG. 1. A representative paper chromatogram of: (1) seminal plasma extract (M. eugenii); (2) hydrolysed seminal plasma extract (M. eugenii); (3) hydrolysed N-acetylglucosamine; a, N-acetylglucosamine; b, fructose; c, glucose; d, glucosamine; e, inositol; using Pr Et Ac, $n$-propanol : ethyl acetate : water, solvent.

siderable quantities of glucose were detected (Text-fig. 1). These results are in accord with analyses of the prostatic secretions (Rodger \& White, 1973, 1974). Paper chromatography also indicated the presence of inositol, a common constituent of mammalian seminal plasma (Text-fig. 1). 
Trimethylsilyl ether derivatives of the semen extracts and of $\mathrm{N}$-acetylglucosamine (Calbiochem, San Diego, California) were prepared by the 'improved' reagent of Carter \& Gaver (1967) and examined by gas-liquid chromatography (column packed with $3 \% \mathrm{OV}-17$ on chromasorb, Deltron Instruments, Aust., isothermal temperature $180^{\circ} \mathrm{C}$ ). The retention times were identical for $\mathrm{N}$-acetylglucosamine and the major constituent of the seminal plasma extracts. Quantitative analyses of seminal plasma extracts from the three macropods by the modified Morgan-Elson method of Reissig, Strominger \& Leloir (1955) revealed a concentration of $\mathrm{N}$-acetylhexosamine equivalent to 100 to $900 \mathrm{mg} \mathrm{N}$-acetylglucosamine/100 g seminal plasma. These levels of $\mathrm{N}$-acetylglucosamine are similar to those of fructose in the seminal plasma of eutherians in which fructose is a major seminal constituent.

The $\mathrm{N}$-acetylamino sugars are common in nature but they invariably occur bound in polysaccharides. It is unlikely that this free $\mathrm{N}$-acetylglucosamine is involved in polysaccharide formation as the polysaccharide synthetic pathways do not utilize free $\mathrm{N}$-acetylglucosamine. Terminal sugars in polysaccharides on the surface of spermatozoa, specifically $\mathrm{N}$-acetylglucosamine, have recently been shown to be important in sperm-egg interactions (Nicolson \& Yanagimachi, 1972; Oikawa, Yanagimachi \& Nicolson, 1973). Involvement of the free $\mathrm{N}$-acetylglucosamine of marsupial seminal plasma in this type of surface effect is an intriguing possibility as marsupial spermatozoa appear to be exposed to the constituents of the seminal plasma for a much longer period than are the spermatozoa of eutherian species. After copulation, marsupial semen is mixed with a considerable quantity of mucous material produced by secretory areas of the vaginal epithelium and this mucus-semen mixture is held in enlarged pockets or sections of the anatomically complex vagina, presumably as a sperm reservoir because ovulation may not occur till $48 \mathrm{hr}$ after oestrus (Hughes \& Rodger, 1971). Human spermatozoa, unlike the epithelial cells of the female tract, can utilize glucosamine, a constituent of cervical mucus, at the time of ovulation (Terner, 1965). A similar rôle for the $\mathrm{N}$-acetylglucosamine of marsupial semen is quite conceivable provided the acetyl group is removed, perhaps by enzymatic constituents of the vaginal mucus.

The authors are indebted to Professor C. W. Emmens for his interest and advice, to Dr M. A. Messer for criticism of the manuscript and to the N.S.W. National Parks and Wildlife Service and Mr P. Davis, 'Brookland Park', Kangaroo Island, South Australia for assistance in obtaining material. The work has been supported by funds from the Australian Research Grants Committee.

\section{REFERENGES}

CARTER, H. E. \& GAVER, R. C. (1967) Improved reagent for trimethylsilylation of sphingolipid bases. 7. Lipid Res. 8, 391.

Hugres, R. L. \& Rodger, J. G. (1971) Studies on the vaginal mucus of the marsupial Trichosurus vulpecula. Aust. F. Zool. 19, 19.

Nicolson, G. L. \& Yanagimachi, R. (1972) Terminal saccharides on sperm plasma membranes: identification by specific agglutins. Science, N.Y. 177, 276.

Oikawa, T., Yanagimachi, R. \& Nicolson, G. L. (1973) Wheatgerm agglutin blocks mammalian fertilization. Nature, Lond. 241, 256. 
Reissig, J. L., Strominger, J. L. \& Leloir, L. F. (1955) A modified colorimetric method for the estimation of $\mathrm{N}$-acetylamino sugars. 7. biol. Chem. 217, 959.

Rodger, J. C. \& Hughes, R. L. (1973) Studies of the accessory glands of male marsupials. Aust. $\mathcal{F}$. Zool. 21, 303.

Rodger, J. C. \& White, I. G. (1973) Carbohydrates of the prostate of marsupials. F. Reprod. Fert. 32, 339.

RoDger, J. C. \& White, I. G. (1974) Carbohydrates of the prostate of two Australian marsupials, Trichosurus vulpecula and Megaleia rufa. 7. Reprod. Fert. 39, 267.

Terner, C. (1965) Oxidative and biosynthetic utilization by human spermatozoa of a metabolite of the female reproductive tract. Nature, Lond. 208, 1115.

Trevelyan, W. E., Procter, D. P. \& Harrison, J. S. (1950) Detection of sugars on paper chromatograms. Nature, Lond. 166, 444.

Werner, W., Rey, H. G. \& WeILINGer, H. (1970) On the properties of a new chromagen for the determination of glucose in the blood according to the GOD/POD method. Z. analyt. Chem. 252, 224. 